\title{
Micro-FTIR spectroscopy and partial least-squares regression for rapid determination of moisture content of nanogram-scaled heat-treated wood
}

\author{
Hanmeng Yuan ${ }^{1}$, Shiyao Tang ${ }^{2}$, Qiuyan Luo ${ }^{1}$, Teng Xiao ${ }^{1}$, Wenlei Wang ${ }^{1}$, Qiang Ma ${ }^{1}$, Xin Guo ${ }^{1 *}$ and Yiqiang Wu ${ }^{2 *}$
}

\begin{abstract}
Moisture sorption has a significant impact on the performance of heat-treated wood. In order to better characterize moisture sorption of heat-treated wood, a method for rapid determination of moisture content (MC) of nanogramscaled heat-treated wood is proposed in this work. During moisture adsorption process, micro-Fourier transform infrared (FTIR) spectra of heat-treated wood were recorded. Spectral analysis was applied to these measured spectra, and then moisture adsorption sites and spectral ranges affected by moisture sorption were identified. Meanwhile, moisture contents (MCs) of heat-treated wood at various relative humidity $(\mathrm{RH})$ levels were measured by using dynamic vapor sorption (DVS) setup. Based on these spectral ranges and MCs, a quantitative forecasting model was established using partial least-square regression (PLSR). Furthermore, the developed forecasting model was applied to acquire moisture sorption isotherm of heat-treated wood, in which a very positive correlation between predicted and measured MCs was observed. It was confirmed that this method was effective for rapid detection of MC of nanogram-scaled heat-treated wood which had unique advantages of rapid analysis (second level) and less sample consumption (nanogram level).
\end{abstract}

Keywords: Moisture sorption, Micro-FTIR spectroscopy, Partial least-squares regression

\section{Introduction}

Wood is a green and renewable building material, and it has been widely used in construction industry, furniture production and pulping and papermaking industry [1-3]. Heat treatment is considered to be an effective technique for wood physical modification, while moisture sorption has a significant impact on the performance of heat-treated wood [4-7]. Hence, a deeper research on moisture sorption of heat-treated wood is extremely important.

\footnotetext{
*Correspondence: guocumt@163.com; wuyq0506@126.com

${ }^{1}$ College of Science, Central South University of Forestry and Technology, Changsha 410004, China

${ }^{2}$ College of Material Science and Engineering, Central South University of Forestry and Technology, Changsha 410004, China
}

Moisture sorption, an important property of heattreated wood, has been studied from various aspects [8-10]. Moisture content (MC) is one of the key aspects, which is mainly measured by gravimetric methods, especially dynamic vapor sorption (DVS). For example, Metsä-Kortelainen et al. [11] confirmed that heat-treated Scots pine (Pinus sylvestris) and Norway spruce (Picea abies) have lower MCs than those untreated samples whose dimensions were $22 \times 65 \times 150 \mathrm{~mm}^{3}$. Besides, Hill et al. [12] employed the DVS apparatus to acquire MCs of heat-treated Scots pine (Pinus sylvestris L.) in the relative humidity (RH) range from 0 to $95 \%$. Further, using DVS apparatus, the sorption isotherms of other heat-treated wood including acacia (Acacia mangium) [13], sesendok (Endospermum malaccense) [14], scots pine (Pinus sylvestris L.) [15-17] and Eucalyptus pellita [18] were 
determined. Although the results are promising, DVS technique is blocked in certain problems, such as sample consumption (milligram level) and experiment time (minute level).

Many spectroscopic methods such as near-infrared spectroscopy [19, 20], Fourier transform infrared spectroscopy (FTIR) [21-23] and Raman spectroscopy [24] have been employed to study moisture sorption of heattreated wood at molecular level. For example, Esteves et al. [25] demonstrated that the near-infrared spectroscopy has enough ability to predict MC of heat-treated pine (Pinus pinaster) and eucalypt (Eucalyptus globulus). Boonstra et al. [26] took advantage of FTIR spectroscopy to study the moisture sorption, and showed that the decrease in MC of heat-treated wood was attributed to the cross-linking of lignin and the reducing of $\mathrm{OH}$ group. Guo et al. [24] examined moisture sorption using Raman spectroscopy. Among these spectroscopic methods, FTIR spectroscopy has been widely applied, for it has many merits, for example: high spectral quality [27, 28], fast data collection speed [29-32], higher signal-to-noise ratio [33, 34], high sensitivity for the detection of moisture [35]. Moreover, micro-FTIR spectroscopy is a superior analytical technique for investigating micron-sized sample [36]. Through the use of a light microscope, an infrared spectrophotometer, a mercury cadmium telluride detector, and an extensive on-line software library of organic chemical spectra, this new technique is capable of identifying micron-scaled sample.

Considering that micro-FTIR spectroscopy has the ability to study micron-sized sample [37, 38], in this study, we developed a method for rapid detection of MC of nanogram-scaled heat-treated wood. First, we collected micro-FTIR spectra of nanogram-scaled heattreated wood during moisture adsorption process. Second, these collected spectra were used to determine moisture sorption sites and spectral ranges correlated with moisture sorption. Third, on account of these determined spectral ranges and measured MCs, the micro-FTIR forecasting model was generated. Finally, the developed forecasting model was applied to acquire moisture sorption isotherm of nanogram-scaled heattreated wood.

\section{Materials and methods}

\section{Sample preparation}

Wood specimens (dimensions $100 \times 30 \times 10 \mathrm{~mm}$ in length, width, and thickness) were collected from straight stem of Ginkgo biloba L. (Ginkgoaceae). Then heat treatment was used for these wood specimens in electric vacuum drying oven under controlled condition of $180 \pm 1{ }^{\circ} \mathrm{C}$. This heat treatment lasted $4 \mathrm{~h}$. From these heat-treated wood specimens, transverse sections were prepared without embedding and any chemical treatment. These sections, $5 \mathrm{~mm} \times 5 \mathrm{~mm} \times 10 \mu \mathrm{m}$, were cut using a manual rotary microtome (Leica RM2135). Prior to the spectral measurement, the transverse section of heat-treated wood specimen was dried at $102 \pm 3{ }^{\circ} \mathrm{C}$ in the oven for $2 \mathrm{~h}$.

\section{Experimental setup for measurement of micro-FTIR spectroscopy}

Figure 1a shows an experimental setup for measurement of micro-FTIR spectroscopy. The main section of the experimental setup was a spectrometer (Nicolet IN 10). This spectrometer included one microscope which provided a new function for selecting observation area. During the spectral measurement, one observation area ( $30 \mu \mathrm{m}$ by $30 \mu \mathrm{m}$ ) was randomly selected in the transverse section of heat-treated wood specimen, in which small quantities $(\sim 1 \mathrm{ng})$ of heat-treated wood was present. The micro-FTIR spectroscopy in the wavenumber

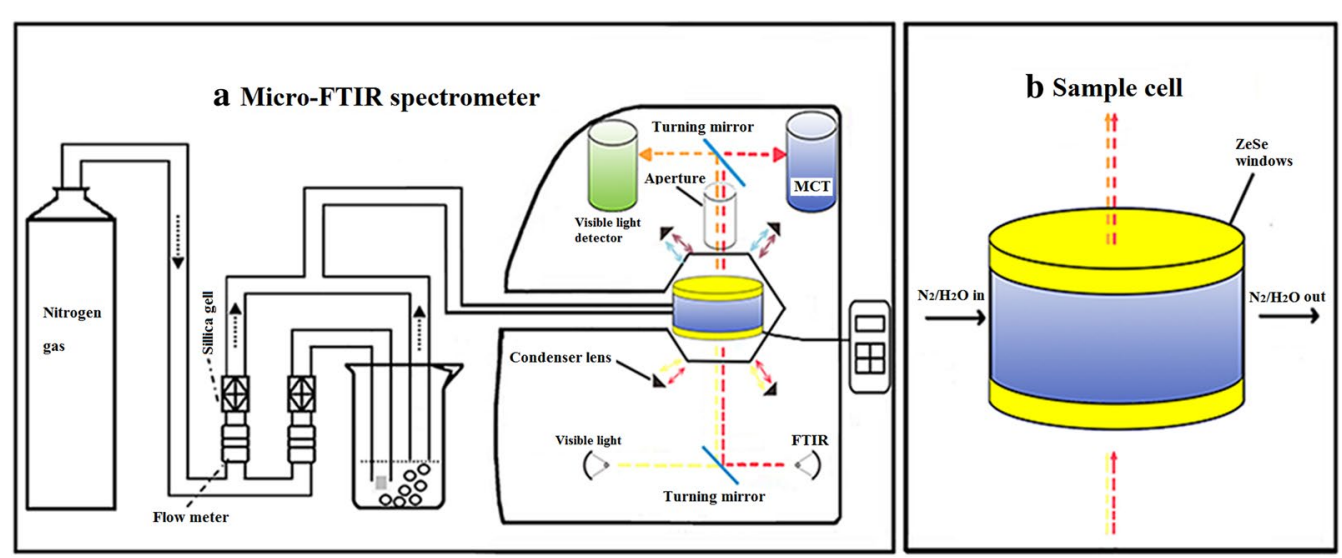

Fig. 1 Experimental setup for measurement of micro-FTIR spectroscopy 
range from 720 to $4000 \mathrm{~cm}^{-1}$ was recorded with $4 \mathrm{~cm}^{-1}$ resolution; 32 scans were collected. Meanwhile, the spectral data were recorded at a constant temperature of $25^{\circ} \mathrm{C}$. Figure $1 \mathrm{~b}$ shows the sample cell. One prepared transverse section was placed on the base of sample cell which was made of $\mathrm{ZnSe}$ plate. Then this sample cell was mounted on the stage of the spectrometer. Meanwhile, through this sample cell, nitrogen gas with specific RH was circulated.

Before the spectral measurement, a kinetic spectroscopy test was conducted to calculate the balance time. Figure 2 shows typical changes of the set $\mathrm{RH}$, the real $\mathrm{RH}$, temperature and peak height of real-time spectrum with time. When the set $\mathrm{RH}$ was changed to a new value (such as 5 and 10\%), the latency of 3-4 min appeared. During the latency period, the real $\mathrm{RH}$ was more and more close to the set $\mathrm{RH}$, and then arrived at stabilization. Meanwhile, 15 min later the real-time spectrum nearly did not change (peak height of the main peak at $3352 \mathrm{~cm}^{-1}$ associated with moisture sorption was advocated to detect spectral change). Based on these results, $60 \mathrm{~min}$ were set as the balance time.

\section{Determination of MC using DVS apparatus}

Moisture content was measured using DVS apparatus (DVS AdvantagePlus). First, a heat-treated wood sample was put on the sample tray which was hung on the microbalance which was situated in a thermostatically controlled cabinet. The apparatus recorded sample mass at the set RH (adsorption): $0,5,10,15,20,25,30,35,40$, $45,50,55,60,65,70,75,80,85,90$ and $95 \%$, at a temperature of $25^{\circ} \mathrm{C}$ and in the reverse sequence for the desorption isotherm. Meanwhile, every set $\mathrm{RH}$ was maintained for enough time until the sample mass of the heat-treated wood specimen altered less than $0.002 \%$ per minute during $10 \mathrm{~min}$.

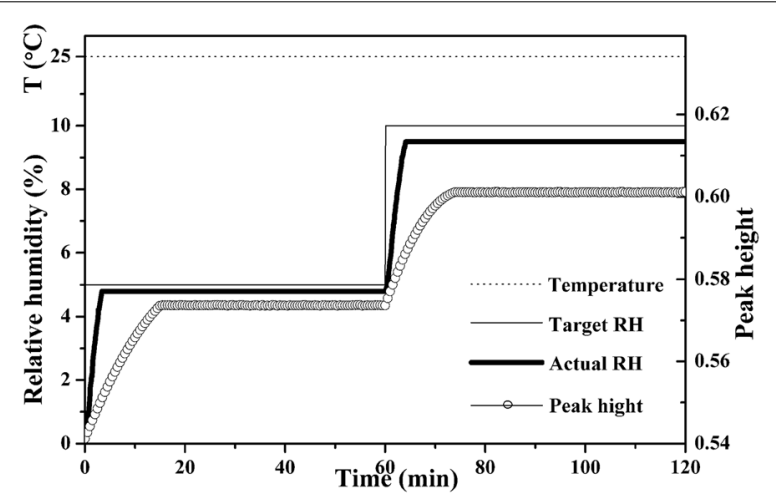

Fig. 2 Typical changes of the set $\mathrm{RH}$, the real $\mathrm{RH}$, temperature and peak height of real-time spectrum with time
Moisture content was calculated using the following formula:

$$
\mathrm{MC}=\frac{m-m_{\mathrm{d}}}{m_{\mathrm{d}}} \times 100,
$$

where $m_{\mathrm{d}}$ was dry sample mass and $m$ is real-time sample mass.

Figure 3 shows typical changes of $\mathrm{MC}$ and $\mathrm{RH}$ with time. When the set RH was changed to the next value (for example, 5 and 10\%), a time delay of 4-10 min appeared. During the latency period, the real $\mathrm{RH}$ got close to the set $\mathrm{RH}$, and then arrived at stabilization afterward. Therefore, $\mathrm{MC}$ would increase to a steady value at the set $\mathrm{RH}$ which was recorded as reference value. It should be noticed that three replicates were exposed and each MC collected as reference value was mean of three replicates.

\section{Spectral data processing Acquiring difference spectrum}

To further analyze the moisture sorption of heat-treated wood qualitatively and quantitatively, a difference spectrum technique was introduced.

\section{Establishment of the forecasting model based on micro-FTIR spectra}

A micro-FTIR forecasting model was generated using TQ Analyst $^{\mathrm{TM}}$ qualitative and quantitative analysis software, one of the OMINIC software suites. In description table, quantitative analysis was set to "partial least squares". In pathlength table, pathlength type was set to "constant". In components table, component was set to "moisture content" whose maximum and minimum values were both entered, and these two values were acquired using DVS apparatus. In standards table, sample spectra collected at 35 different relative humidities were introduced. Fourfifths of sample spectra measured at 28 different relative

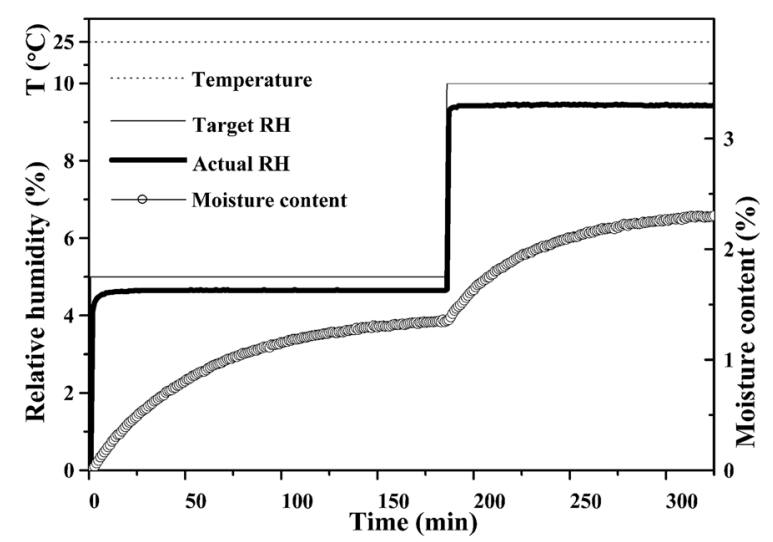

Fig. 3 Typical changes of $M C$ and $R H$ vs. time 
humidities with six replicates (i.e., 168 spectra) were assigned to the calibration set, and the remaining sample spectra acquired at seven different relative humidities with six replicates (i.e., 42 spectra) were allocated to the validation set. In spectra table, no smoothing and multipoint baseline correction were programmed. In regions table, spectral range was adjusted according to the qualitative description of heat-treated wood moisture sorption. When these parameters were enabled, the TQ Analyst $^{\mathrm{TM}}$ qualitative and quantitative analysis software program was run, and one forecasting model was established. Model performance was estimated using the correlation of determination $\left(R^{2}\right)$, root-mean-square error of cross-validation (RMSECV) and root-mean-square error of prediction (RMSEP).

\section{Results and discussion}

\section{Qualitatively analyzing moisture sorption in heat-treated} wood

Figure 4 shows heat-treated wood spectra collected at the moisture adsorption process. The development of micro-FTIR spectra could be seen over a range of MC from 0 to $15.0 \%$ in this figure. At the MC of $15.0 \%$, the main band at $3358 \mathrm{~cm}^{-1}$ assigned to $\mathrm{O}-\mathrm{H}$ stretching vibration increased, showing the $\mathrm{OH}$ group was moisture adsorption sites of heat-treated wood. The band at $1736 \mathrm{~cm}^{-1}$ was assigned to $\mathrm{C}=\mathrm{O}$ stretching vibration of carboxylic acid, the $1600 \mathrm{~cm}^{-1}$ band belonged to the aromatic skeletal vibration plus the $\mathrm{C}=\mathrm{O}$ stretching vibration, and the band at $1158 \mathrm{~cm}^{-1}$ was attributed to the glucosidic $\mathrm{C}-\mathrm{O}-\mathrm{C}$ vibration. For comparison, heattreated wood spectrum measured at $0 \% \mathrm{MC}$ was also displayed, in which these three bands appeared at 1739, 1604 , and $1160 \mathrm{~cm}^{-1}$. When RH increased, the band positions of these three bands exhibited continuous red shifts. These peak shifts indicated the carbonyl and $\mathrm{C}-\mathrm{O}$ groups were moisture adsorption sites of heattreated wood. What's more, it was confirmed that two micro-FTIR spectral ranges correlated with moisture sorption were $3700-3100$ and $1780-1700 \mathrm{~cm}^{-1}$.

Figure 5 presents difference spectra at various MC levels during the moisture adsorption process. The broad envelope range of $3700-2800 \mathrm{~cm}^{-1}$ containing many component bands was observed to rise which resulted from moisture sorption. Further, the first spectral range correlated with moisture sorption was precisely identified as from 3700 to $2800 \mathrm{~cm}^{-1}$. Meanwhile, the $1755 \mathrm{~cm}^{-1}$ band belonged to free carbonyl group decreased, while the $1725 \mathrm{~cm}^{-1}$ band was assigned to hydrogen bonded carbonyl group had reverse trend. Meanwhile, the band around $1642 \mathrm{~cm}^{-1}$ was assigned to $\mathrm{H}-\mathrm{O}-\mathrm{H}$ bending vibration. Therefore, second spectral range was precisely identified as from 1770 to $1580 \mathrm{~cm}^{-1}$. Moreover, with an increase of $\mathrm{RH}$, the $1171 \mathrm{~cm}^{-1}$ band was shown to decrease, while the $1142 \mathrm{~cm}^{-1}$ band was found to rise. The same reflections were happened in two bands located at 1171 and $1142 \mathrm{~cm}^{-1}$. This further suggested the third spectral range correlated with moisture sorption could be precisely confirmed as from 1180 to $1140 \mathrm{~cm}^{-1}$.

Further, the variation in the peak height for three peaks impacted by water sorption vs. MC is shown in Fig. 6. Clearly the variation for three peaks was diverse, suggesting that water molecule was absorbed by all these sorption sites. However, none of these three peaks could predict moisture sorption isotherm. Therefore, a method for determination of MC of heat-treated wood is needed urgently.
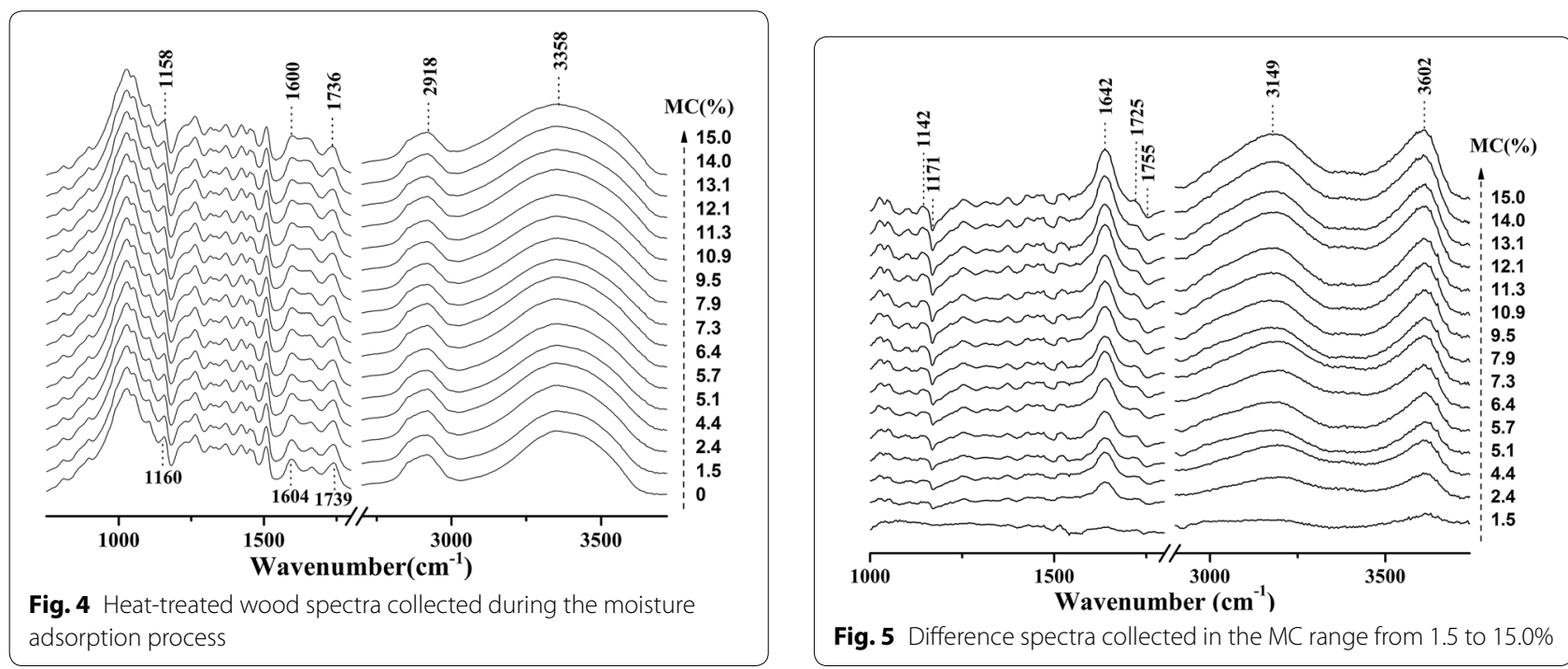

Fig. 5 Difference spectra collected in the MC range from 1.5 to $15.0 \%$ 


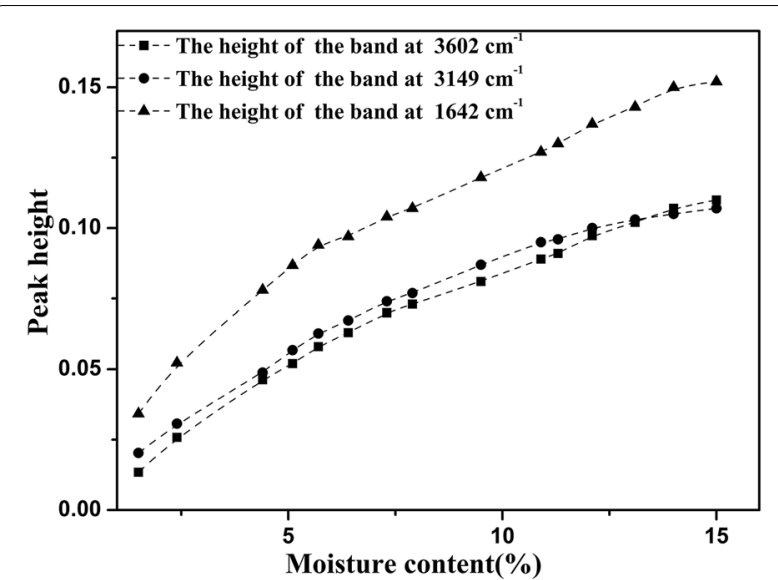

Fig. 6 The variation in the peak height for three peaks impacted by moisture sorption vs. MC. Quadrate dot: the $3602 \mathrm{~cm}^{-1}$ band. Circular dot: the $3149 \mathrm{~cm}^{-1}$ band. Triangle dot: the $1642 \mathrm{~cm}^{-1}$ band
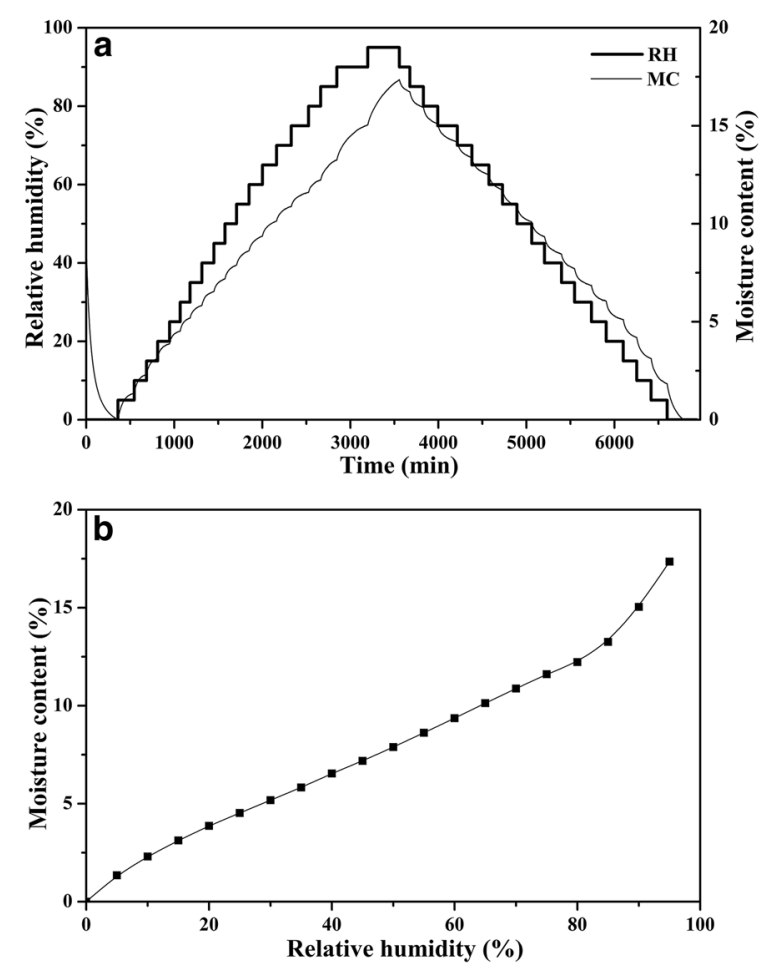

Fig. 7 a Change in moisture content of heat-treated wood with the varying $\mathrm{RH}$ levels over the time profile in the isotherm run. $\mathbf{b}$ Equilibrium moisture content of heat-treated wood over the full set $\mathrm{RH}$ range in the adsorption process

\section{Quantitative detection of MC of heat-treated wood}

As shown previously, DVS has offered vast amounts of moisture sorption isotherms [39-41]. Hence, this technique was introduced to collect MCs as measured values. Figure 7 shows the experimental sorption isotherm. This isotherm curve presented a typical sigmoidal shape commonly observed for other lignocellulosic materials [42].

In order to establish a method for rapid determination of $\mathrm{MC}$, the forecasting model based on micro-FTIR spectroscopy ought to be determined firstly. As mentioned earlier, spectral range was an important parameter for the forecasting model. Three spectral ranges of 3700$2800,1770-1580$, and $1180-1140 \mathrm{~cm}^{-1}$ correlated with moisture sorption were proposed as Case A. Further, the widened and narrowed spectral ranges were introduced separately as Case B and C (Case B: 3700-2800, 2800-2700, 1770-1580, and $1180-1140 \mathrm{~cm}^{-1}$; Case C: $3700-3000,1770-1580$, and $1180-1140 \mathrm{~cm}^{-1}$ ). In all three cases, the micro-FTIR forecasting model was generated and corresponding parameters such as RESECV, RESEP, and $R^{2}$ could be acquired in TQ Analyst ${ }^{\mathrm{TM}}$ software (as shown in Table 1). The established forecasting model in Case A had highest forecast accuracy, for it possessed highest values of $R^{2}$ as well as the lowest values of RMSEP and RMSECV. What's more, this model made use of the whole spectral ranges correlated with moisture sorption, and the change of spectral range (increase and decrease) could decrease the accuracy of the established forecasting model in Case B and C.

Based on the established forecasting model, MCs of heat-treated wood were predicted. Moreover, measured values using DVS setup are displayed in Fig. 8. During the moisture adsorption process, the predicted MCs were much closed to the measured values (relative error was lower than 3\%). Results indicated that this method for rapid detection of MC in nanogram-scaled heat-treated wood using micro-FTIR spectroscopy and partial leastsquares regression was effective and efficient. Compared to the traditional DVS, it has unique advantages of rapid analysis (second level) and less sample consumption (nanogram level).

\section{Conclusion}

One method for rapid determination of moisture content of nanogram-scaled heat-treated wood was proposed here. Micro-FTIR spectra were measured during the moisture adsorption process. An analysis of these spectra confirmed that hydroxyl and carbonyl groups were moisture sorption sites of heat-treated wood. Moreover, three spectral ranges, such as $3700-2800$, $1770-1580$, and $1180-1140 \mathrm{~cm}^{-1}$ were identified that related to moisture sorption. Based on these three spectral ranges and referential values, a quantitative forecasting model was built using PLSR. Further, the developed forecasting model was applied to acquire moisture sorption isotherm of heat-treated wood, in which a very positive correlation between the forecasts and recorded values. It was confirmed that this method 
Table 1 PLSR quality parameters for cross- and test set-validation for the proposed three cases

\begin{tabular}{llll}
\hline & First case & Second case & Third case \\
\hline Spectral region $\left(\mathrm{cm}^{-1}\right)$ & $3700-2800 / 1770-1580 / 1180-1140$ & $3700-2800 / 2800-2700 / 1770-$ & $3700-3000 / 1770-$ \\
Cross-validation & & & $1580 / 1180-1140$ \\
RMSECV (\%) & 50.5 & 73.6 & 54.3 \\
Number of PLS components & 6 & 6 & 6 \\
$R^{2}$ & 0.9945 & 0.9898 & 0.9937 \\
External validation & 19.3 & 28.9 & 25.2 \\
RMSEP (\%) & 6 & 6 & 6 \\
Number of PLS components & 0.9988 & 0.9982 & 0.9976 \\
$R^{2}$ & & & \\
\hline
\end{tabular}

RMSECV: root-mean-square error of cross-validation; RMSEP: root-mean-square error of prediction; $R^{2}$ : coefficient of determination

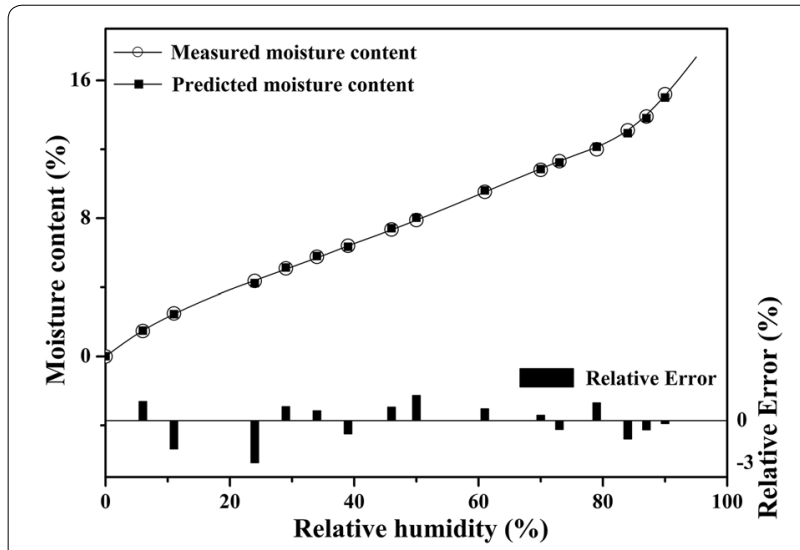

Fig. 8 Moisture sorption isotherm estimated by micro-FTIR forecasting model and that measured by DVS approach. Solid quadrate spot: MCs predicted using micro-FTIR forecasting model. Hollow circular spot: MCs measured using DVS setup

\section{Authors' contributions}

All the authors have contributed to the manuscript and take all responsibilities for the entire content of the manuscript. All authors read and approved the final manuscript.

\section{Funding}

This study was supported by National Natural Science Foundation of China (Grant Numbers 31890771, 31670563 and 31500475), Special projects of scientific and technological innovation in Hunan forestry (Grant No. XLK201982), Natural Science Foundation of Hunan Province, China (Grant Number 2019JJ50981), Research Foundation of Education Bureau of Hunan Province, China (Grant Number 18A166), and Scientific Innovation Fund for Post-graduates of Central South University of Forestry and Technology (Grant Number CX20192073).

\section{Availability of data and materials}

The datasets used or analyzed during the current study are available from the corresponding author on reasonable request.

\section{Competing interests}

The authors declare that they have no competing interests.

Received: 3 August 2019 Accepted: 8 January 2020

Published online: 16 January 2020

for rapid detection of moisture content in nanogramscaled heat-treated wood was effective which had unique advantages of rapid analysis (second level) and less sample consumption (nanogram level).

\section{Abbreviations}

FTIR: Fourier transform infrared; MCs: moisture contents; $\mathrm{RH}$ : relative humidity; DVS: dynamic vapor sorption; PLSR: partial least-square regression; MC: moisture content; RMSECV: root-mean-square error of cross-validation; RMSEP: root-mean-square error of prediction.

\section{Acknowledgements}

The authors are grateful for the financial support from National Natural Science Foundation of China (Grant Numbers 31890771, 31670563 and 31500475), Special projects of scientific and technological innovation in Hunan forestry (Grant No. XLK201982), Natural Science Foundation of Hunan Province, China (Grant Number 2019JJ50981), Research Foundation of Education Bureau of Hunan Province, China (Grant Number 18A166), and Scientific Innovation Fund for Post-graduates of Central South University of Forestry and Technology (Grant Number CX20192073).

\section{References}

1. Wålinder MEP, Gardner DJ (1999) Factors influencing contact angle measurements on wood particles by column wicking. J Adhes Sci Technol 13:1363-1374

2. Obataya E, Norimoto M, Gril J (1998) The effects of adsorbed water on dynamic mechanical properties of wood. Polymer 39:3059-3064

3. Maeda H, Fukada E (1987) Effect of bound water on piezoelectric, dielectric, and elastic properties of wood. J Appl Polym Sci 33:1187-1198

4. Rekola J, Aho AJ, Gunn J, Matinlinna J, Hirvonen J, Viitaniemi P, Vallittu PK (2009) The effect of heat treatment of wood on osteoconductivity. Acta Biomater 5:1596-1604

5. Kartal SN, Hwang WJ, Imamura Y (2007) Water absorption of borontreated and heat-modified wood. J Wood Sci 53:454-457

6. Salmen L, Possler H, Stevanic JS, Stanzltschegg SE (2008) Analysis of thermally treated wood samples using dynamic FT-IR-spectroscopy. Holzforschung 62:676-678

7. Pelit H, Budakçı M, Sönmez A, Burdurlu E (2015) Surface roughness and brightness of scots pine (Pinus sy/vestris) applied with water-based varnish after densification and heat treatment. J Wood Sci 61:586-594

8. Temiz A, Terziev N, Jacobsen B, Eikenes M (2010) Weathering, water absorption, and durability of silicon, acetylated, and heat-treated wood. J Appl Polym Sci 102:4506-4513 
9. Huang X, Kocaefe D, Kocaefe Y, Boluk Y, Pichette A (2012) Changes in wettability of heat-treated wood due to artificial weathering. Wood Sci Technol 46:1215-1237

10. Wang Y, lida I, Minato K (2007) Mechanical properties of wood in an unstable state due to temperature changes, and analysis of the relevant mechanism IV: effect of chemical components on destabilization of wood. J Wood Sci 53:381-387

11. Metsä-Kortelainen S, Antikainen T, Viitaniemi P (2006) The water absorption of sapwood and heartwood of Scots pine and Norway spruce heat-treated at $170^{\circ} \mathrm{C}, 190^{\circ} \mathrm{C}, 210^{\circ} \mathrm{C}$ and $230^{\circ} \mathrm{C}$. Eur J Wood Wood Prod 64:192-197

12. Hill CAS, Ramsay J, Keating B, Laine K, Rautkari L, Hughes M, Constant B (2012) The water vapour sorption properties of thermally modified and densified wood. J Mater Sci 47:3191-3197

13. Willems W (2014) The water vapor sorption mechanism and its hysteresis in wood: the water/void mixture postulate. Wood Sci Technol 48:499-518

14. Jalaludin Z, Hill CAS, YanJun X, Samsi HW, Husain H, Awang K, Curling SF (2010) Analysis of the water vapour sorption isotherms of thermally modified acacia and sesendok. Wood Mater Sci Eng 5:194-203

15. Hosseinpourpia R, Adamopoulos S, Holstein N, Mai C (2017) Dynamic vapour sorption and water-related properties of thermally modified Scots pine (Pinus sylvestris L.) wood pre-treated with proton acid. Polym Degrad Stabil 138:161-168

16. Kymäläinen M, Mlouka SB, Belt T, Merk V, Liljeström V, Hänninen T, Uimonen T, Kostiainen M, Rautkari L (2018) Chemical, water vapour sorption and ultrastructural analysis of Scots pine wood thermally modified in high-pressure reactor under saturated steam. J Mater Sci 53:3027-3037

17. Hosseinpourpia R, Adamopoulos S, Mai C (2017) Effects of acid pretreatments on the swelling and vapor sorption of thermally modified scots pine (Pinus sylvestris L.) wood. BioResources 13:331-345

18. Sun B, Wang Z, Liu J (2017) Changes of chemical properties and the water vapour sorption of Eucalyptus pellita wood thermally modified in vacuum. J Wood Sci 63:133-139

19. Mitsui K, Inagaki T, Tsuchikawa S (2008) Monitoring of hydroxyl groups in wood during heat treatment using NIR spectroscopy. Biomacromolecules 9:286-288

20. Sandak A, Sandak J, Allegretti O (2015) Quality control of vacuum thermally modified wood with near infrared spectroscopy. Vacuum 114:44-48

21. Akgül M, Gümüşkaya $E$, Korkut S (2007) Crystalline structure of heattreated Scots pine [Pinus sylvestris L.] and Uludağ fir [Abies nordmanniana (Stev.) subsp. Bornmuelleriana (Mattf.)] wood. Wood Sci Technol 41:281-289

22. Özgenç Ö, Durmaz S, Boyaci IH, Eksi-Kocak H (2017) Determination of chemical changes in heat-treated wood using ATR-FTIR and FT Raman spectrometry. Spectrochim Acta A 171:395-400

23. Kotilainen RA, Toivanen TJ, Alén RJ (2000) FTIR monitoring of chemical changes in softwood during heating. J Wood Chem Technol 20:307-320

24. Guo X, Wu Y, Yan N (2016) Characterizing spatial distribution of the adsorbed water in wood cell wall of Ginkgo biloba L. by u-FTIR and confocal Raman spectroscopy. Holzforschung 71:415-423

25. Esteves B, Pereira H (2008) Quality assessment of heat-treated wood by NIR spectroscopy. Holz als Roh- und Werkstoff 66:323-332

26. Boonstra MJ, Tjeerdsma B (2006) Chemical analysis of heat treated softwoods. Holz als Roh- und Werkstoff 64:204-211

27. Gerwert K, Hess B, Michel H, Buchanan S (1988) FTIR studies on crystals of photosynthetic reaction centers. FEBS Lett 232:303-307
28. Zhang J, Zhang X, Zhang F, Yu S (2017) Solid-film sampling method for the determination of protein secondary structure by Fourier transform infrared spectroscopy. Anal Bioanal Chem 409:4459-4465

29. Jangir DK, Charak S, Mehrotra R, Kundu S (2011) FTIR and circular dichroism spectroscopic study of interaction of 5-fluorouracil with DNA. J Photochem Photobiol B 105:143-148

30. Bunaciu AA, Aboul-Enein HY, Fleschin S (2012) FTIR spectrophotometric methods used for antioxidant activity assay in medicinal plants. Appl Spectrosc Rev 47:245-255

31. Amir RM, Anjum FM, Khan MI, Khan MR, Pasha I (2013) Application of Fourier transform infrared (FTIR) spectroscopy for the identification of wheat varieties. J Food Sci Technol 50:1018-1023

32. Ahmad I, Ullah J, Ishaq M, Khan H, Gul K, Siddiqui S, Ahmad W (2015) Monitoring of oxidation behavior in mineral base oil additized with biomass derived antioxidants using FT-IR spectroscopy. RSC Adv 5:101089-101100

33. González-Gaitano G, Isasi JR (2001) Analysis of the rotational structure of $\mathrm{CO}_{2}$ by FTIR spectroscopy. Chem Educ 6:362-364

34. Heidi N, Nils Kristian A, Young JF, Bertram HC, Pedersen ME, Stine G, Gjermund V, Achim K (2011) Monitoring cellular responses upon fatty acid exposure by Fourier transform infrared spectroscopy and Raman spectroscopy. Analyst 136:1649-1658

35. Célino A, Goncalves O, Jacquemin F, Fréour S (2014) Qualitative and quantitative assessment of water sorption in natural fibres using ATR-FTIR spectroscopy. Carbohydr Polym 101:163-170

36. Yong L, Zhiwei Y, Yury D, Gassman PL, Hai W, Alexander L (2008) Hygroscopic behavior of substrate-deposited particles studied by micro-FT-IR spectroscopy and complementary methods of particle analysis. Anal Chem 80:633

37. Guo X, Liu L, Wu J, Fan J, Wu Y (2018) Qualitatively and quantitatively characterizing water adsorption of a cellulose nanofiber film using micro-FTIR spectroscopy. RSC Adv 8:4214-4220

38. He X, Leng C, Pang S, Zhang Y (2017) Kinetics study of heterogeneous reactions of ozone with unsaturated fatty acid single droplets using micro-FTIR spectroscopy. RSC Adv 7:3204-3213

39. Argyropoulos D, Alex R, Kohler R, Muller J (2012) Moisture sorption isotherms and isosteric heat of sorption of leaves and stems of lemon balm (Melissa officinalis L.) established by dynamic vapor sorption. LWT Food Sci Technol 47:324-331

40. Garbalinska H, Bochenek M, Malorny W, Von Werder J (2017) Comparative analysis of the dynamic vapor sorption (DVS) technique and the traditional method for sorption isotherms determination-exemplified at autoclaved aerated concrete samples of four density classes. Cement Concr Res 91:97-105

41. Fang L, Xiong X, Wang X, Hong C, Mo X (2016) Effects of surface modification methods on mechanical and interfacial properties of high-density polyethylene-bonded wood veneer composites. J Wood Sci 63:65-73

42. Avramidis S (1989) Evaluation of "three-variable" models for the prediction of equilibrium moisture content in wood. Wood Sci Technol 23:251-257

\section{Publisher's Note}

Springer Nature remains neutral with regard to jurisdictional claims in published maps and institutional affiliations. 